Faculdade

de Ciências Econômicas UFRGS

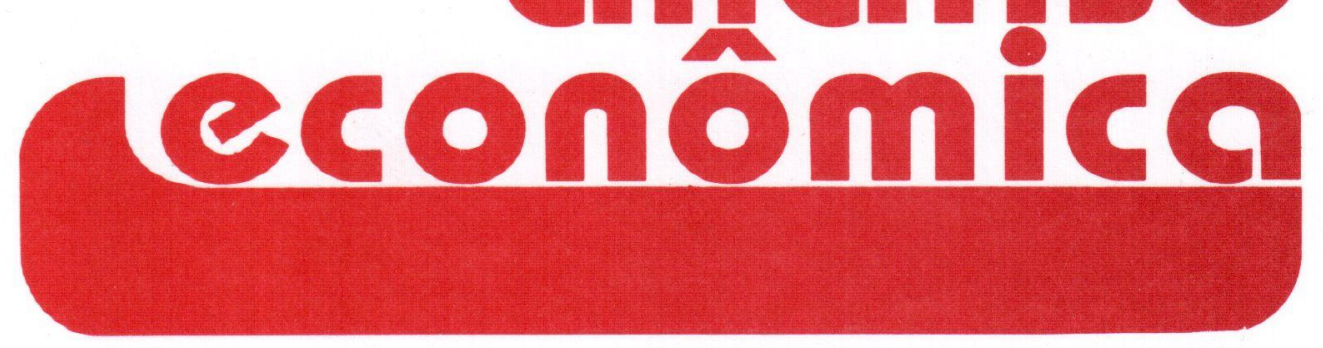

- A INTERNACIONALIzAÇÃo do Sistema FIINANCEIRO: 1990-1992

Lauro Lobo Burle

- GOVERNMENT INTERVENTION, INSTITUTIONAL FACTORS AND MARKET : AN ANALYSIS OF THE WAGE BARGAINING IN BRAZIL

Francisco Galrão Carneiro

- AINSTITUCIONALIZAÇÃO DA PREFERÊNCIA PELA LIQUIDEZ Albério Neves Filho

- PADRÕES MONETÁRIOS ALTERNATIVOS Fernando Carlos G. de Cerqueira Lima

- as contas nacionais e os custos AMBIENTAIS DA ATIVIDADE ECONÓMICA Charles C. Mueller

- LIVROS RECEBIDOS

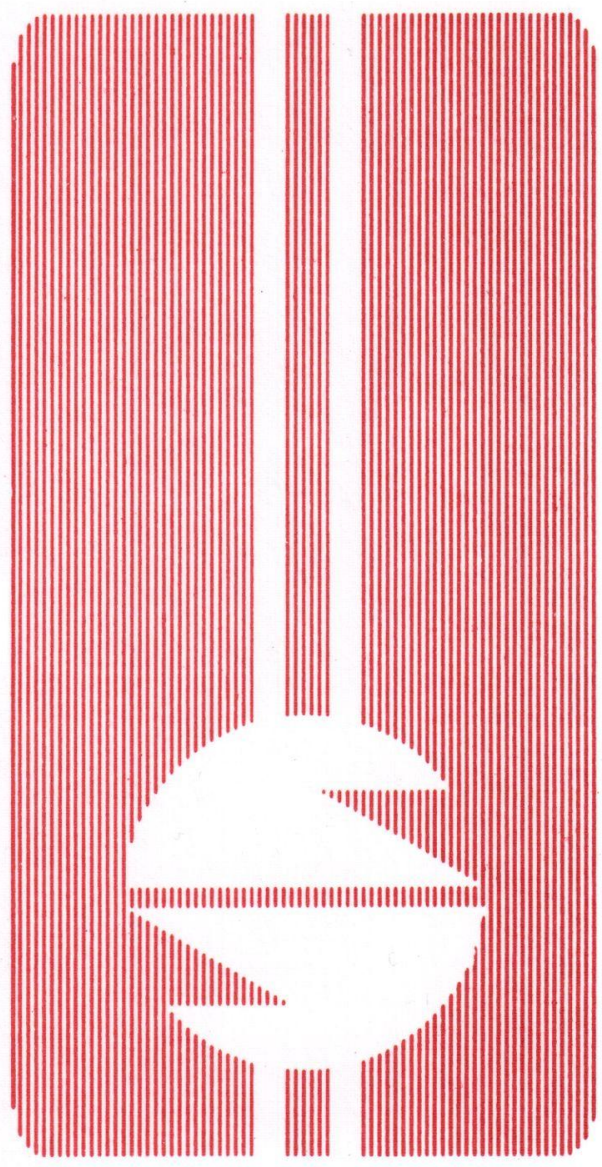


UNIVERSIDADE FEDERAL DO RIO GRANDE DO SUL Reitor Prof. Hélgio Henrique Casses Trindade

FACULDADE DE CIÊNCIAS ECONÔMICAS Diretor. Prof. Pedro Cézar Dutra Fonseca

CENTRO DE ESTUDOS E PEQUISAS ECONÔMICAS

Diretor. Prof. Paulo Alexandre Spohr

DEPARTAMENTO DE CIÉNCIAS ECONÔMICAS

Chefe: Prof. Achyles Barcelos da Costa

CURSO DE PÓS-GRADUAÇÃO EM ECONOMIA

Coordenador. Prof. Roberto Camps Moraes

CURSO DE PÓS-GRADUAÇĀO EM ECONOMIA RURAL

Coordenador. Prof. Atos Freitas Grawunder

CONSELHO EDITORIAL: Achyles Barcelos da Costa, Aray Miguel Feldens, Atos Freitas Grawunder, Carlos Augusto Crusius, Eugênio Lagemann, Fernando Ferrari Filho, Gentil Corazza, Juvir Luiz Mattuella, Marcelo Savino Portugal, Maria Imilda da Costa e Silva, Nali de Jesus de Souza, Nuno R. L. de Figueiredo Pinto, Otília Beatriz K. Carrion, Paulo Alexandre Spohr, Pedro Cezar Dutra Fonseca, Roberto Camps Moraes, Valter José Stülp, David Garlow (Wharton Econometrics Forecasts Association, E. U.A.), Edgar Augusto Lanzer (UFSC), Eleutério F. S Prado (USP), Fernando de Holanda Barbosa (FGV/RJ), Gustavo Franco (PUC/RJ), João Rogério Sanson (UFSC), Joaquim Pinto de Andrade (UnB), Juan H Moldau (USP), Werner Baer (Univ. de lllinois, E. U.A.).

COMISSÃO EDITORIAL: Atos Freitas Grawunder, Pedro Cezar Dutra Fonseca, Marcelo Savino Portugal, Roberto Camps Moraes.

EDITOR: Nali de Jesus de Souza

SECRETARIA: Cláudia Porto Silveira, Jeferson Luis Bittencourt e Vanete Ricachescki (revisão de textos).

FUNDADOR: Prof. Antônio Carlos Santos Rosa

Os materiais publicados na revista Análise Econômica são da exclusiva responsabilidade dos autores É permitida a reprodução total ou parcial dos trabalhos, desde que seja citada a fonte.

Aceita-se permuta com revistas congêneres. Aceitam-se, também, livros para divulgação, elaboração de resenhas e recensões.

Toda correspondência, material para publicaçăo (vide normas na terceira capa), assinaturas e permutas devem ser dirigidos ao seguinte destinatário:

PROF. NALI DE JESUS DE SOUZA

Revista Análise Econômica

Av. Joảo Pessoa, 52

CEP 90040-000 PORTO ALEGRE - RS, BRASIL.

Telefones: (051) 316-3348 e 316-3440

Fax: (051) 225-1067 


\section{A INSTITUCIONALIZAÇÃO DA PREFERÊNCIA \\ PELA LIQUIDEZ: UMA CONTRIBUIÇÃO AO DEBATE}

Albério Neves Filho*

\section{SINOPSE}

O presente artigo analisa o comportamento da firma num contexto de tomada de decisão visando a obtenção de ganhos monetários. Considerando esta idéia, o artigo objetiva estudar a forma como a firma emprega os seus recursos e institucionaliza seus métodos, num sistema econômico tão volátil como o que se apresenta atualmente. Primeiramente é discutido como a firma obtém seus ganhos monetários; posteriormente aborda-se o processo de transformação dos recursos físicos em produtos. Finaliza-se com uma análise da utilização, não somente de ativos reais, mas também de ativos monetários pela firma para que se realize o lucro monetário almejado.

\section{INTRODUÇÃO}

Reavaliar continuamente os investimentos realizados e, por certo, as condições que envolvem os potenciais investimentos a serem realizados é uma determinação imposta pela economia monetária de produção que possui um moderno sistema monetáriofinanceiro. Seu desenvolvimento, à base de grandes instabilidades, colocou na ordem do dia para as empresas a necessidade de convencionalizarem procedimentos frente ao caráter monetário desse novo quadro econômico e as incertezas, associadas às expectativas de longo prazo, dele decorrentes.

Para convencionalizar procedimentos, a firma deverá supor tanto a continuidade da situação existente, quanto a alteração dessa, decorrente do movimento da própria economia. O controle dos efeitos incertos gerados pelas suposição acima é a razão pela qual a empresa buscará, sempre que possivel, institucionalizar seus procedimentos. Daí as implicações desse seu movimento institucionalizado em uma economia monetária. Como sabemos, a empresa em uma economia monetária de produção é o espaço onde se elabora a estratégia e se toma decisões, com o objetivo principal de produzir e obter lucros monetários, aumentando-se, dessa forma, continuamente sua possibilidade de crescimento. Assim, ao transformar recursos reais e/ou financeiros em produtos e ao produzir novos métodos de produção, a empresa visa, em primeira instância, aumentar sua capacidade de obter lucro monetário em quantidade crescente.

Simultâneo a esse aspecto, a empresa ao atuar por sobre um ambiente externo que the aparece como "cenário", servindo enquanto tal de suporte às suas açōes, ao mesmo tempo que lhe surge um ambiente volátil, estritamente real, que determina suas prováveis decisões - cujas consequeencias terminam por remodelar esse mesmo ambiente - terá sua trajetória de crescimento marcada pela sua maior ou menor capacidade de institucionalizar procedimentos que recaem e the dêem controle sobre os determinantes monetáriosfinanceiros responsáveis pela obtenção de maiores margens de lucro e de riqueza, obtidos e medidos monetariamente. Viabilizar os recursos e os procedimentos institucionalizadores que tornam isso possível eis a sua marca e o que é aqui tratado.

\footnotetext{
"Professor de Economia UNESP- Depto. Direito Público. Doutorando em Economia UNICAMP.
}

\begin{tabular}{|c|l|}
\hline $\begin{array}{c}\text { Cód. AEA } \\
521\end{array}$ & $\begin{array}{l}\text { Palavras-chave: objetivos da firma, demanda por moeda, teoria do } \\
\text { portfólio. }\end{array}$ \\
\hline
\end{tabular}

\begin{tabular}{|l|l|l|l|}
\hline ANÁLISE ECONÔMICA & ANO 12 & março/setembro 95 & p. 37-46 \\
\hline
\end{tabular}


De inicio, revemos as implicações do argumento inicial. Primeiro, nos informa que a atuação da firma em uma economia monetária de produção leva à busca de ganhos monetários como seu objetivo central. Segundo, implica, também que seu ponto de partida real, isto é, a transformação de recursos fisicos em produtos, é coberto por um véu monetário no sentido de que, para realizar aqueles ganhos monetários alvejados, deve financiar monetariamente o investimento necessário para tais fins. Finalmente, ao atuar em um tempo histórico e em um ambiente onde não controla todas as variáveis presentes, a firma se move em um mundo que the aparece como incerto. Nesse quadro de incerteza, obter lucros monetários excedentes, utilizando-se de ativos reais não é o único fator fundamental, mas também manter-se em situação de liquidez em todo o periodo é igualmente vital, pois, dessa forma, a firma sintetiza tempo e incerteza enquanto fenômenos meramente monetários, passiveis de serem administrados e "conhecidos" nessa forma. De outro modo, a firma pode instituir um conhecimento prático sobre o futuro, convencionalizando procedimentos cuja referência recai sobre sua performance monetária.

Dessa condição deve derivar aquilo que lhe aparece como problema fundamental, qual seja: o de se manter flexível o suficiente para gerar rendimentos monetários em escala crescente por todo o periodo produtivo, os quais serão medidos em dinheiro. De outra forma, suposta uma economia monetária de produção, onde o elemento determinante dos rendimentos parece ser a liquidez, a firma organiza suas decisões econômicas através da adoção de uma estratégia que responda às melhores combinações a serem obtidas entre dinheiro, produção e geração de mais dinheiro.

Vale dizer, então, a problematização da e para a firma gira em torno da dinâmica da liquidez, formulação de estratégias, composição e financiamento do portfólio e decisões de investimento, produção e preços que possam gerar rendimentos monetários excedentes, pois, na dinámica dessa economia, a avaliação da riqueza e do próprio processo de reprodução do capital surge na forma monetária do valor. Um último aspecto precisa ser afirmado. O ambiente externo é volátil e, portanto, quase sempre desconhecido, sendo um fator hostil frente aos objetivos que se persegue. Logo, atuar nesse ambiente é reagir às ações dos concorrentes, do Estado e, como veremos adiante, do próprio sistema financeiro responsável pelo financiamento dos investimentos.

Aqui vamos tratar, precisamente, do problema fundamental da firma em uma economia monetária de produção, cuja dinâmica é determinada pela dominância financeira dos vínculos entre liquidez e produção. Para tanto, realizaremos uma exposição sobre a liquidez, sua articulação $\mathrm{com}$ a elaboração dos objetivos estratégicos da firma, direcionados a captura de dinheiro (inclusive nas diversas faces de quase-dinheiro ou dinheiro bancário) e os vínculos entre liquidez, estratégia, composição e financiamento do portfólio. Desde já, somos guiados pela hipótese, de que, para a firma obter rendimentos monetários excedentes, em uma economia dominada pela preferência pela liquidez, deverá flexibilizar e manter comerciável seu conjunto de ativos de seu portfólio. $E$ aqui se concentram, ao nosso ver, suas dificuldades de crescimento.

\section{TEMPO, INCERTEZA E DINHEIRO: PREOCUPAÇÕES PÓS- KEYNESIANAS}

Uma síntese dos postulados da visão pós-keynesiana nos será bastante útil frente aos nossos objetivos. Se bem compreendemos, a teoria econômica monetária de produção de acento pós-keynesiano tem, como elemento mais dinâmico, a busca da construção de uma concepção de mundo, a qual the permite redefinir continuamente, como um todo, 0 próprio objeto da ciência econômica, retirando-o da esterilidade imputada pelas diversas visões clássicas, neoclássicas e congêneres, postuladoras de um mundo a-histórico, sem tempo ou incertezas, e de uma economia de caráter cooperativo. Para tanto, na raiz de sua concepção alternativa, introduzem como objeto de estudo, o tempo, a incerteza e o 
dinheiro é que se condensa o projeto teórico como processo histórico, condensaçäo essa que se abre como um leque, possibilitando vários caminhos para a reflexão.

Aos fins aqui previstos, tempo, incerteza e dinheiro são fatores relevantes para a ação da firma. Na definição proposta por esses autores, a firma é um espaço de acumulação e valorização de capital onde, de um lado, para realizar esse seu "destino manifesto" deverá produzir bens, produção essa demandadora de tempo e, de outro lado, deverá completar sua produção obtendo mais dinheiro ao final do que mantinha no inicio do processo. Obviamente, a realização desse seu destino é incerto visto que o capitalista pode decidir sobre o que e quanto produzir, mas não pode decidir sobre o quanto ganhará (se for o caso) pela quantidade produzida

Primeiro, portanto, observemos a relevância do tempo. A despeito desse ser irreversivel e unidirecional, corn custos monetários evidentes à reversão de decisões já tomadas, o tempo de tomada de decisăo será sempre um tempo presente, com implicações sobre a situação econômica da firma (no presente e no futuro); sobre as decisőes potenciais relacionadas ao curso dos negócios (tecnologia e mercado) e o conhecimento mais aprimorado possível da firma do(s) mercado(s) em que atua. Ao lado desse, outros aspectos relacionados ao fenômeno tempo, abatem-se sobre a firma. Por exemplo, em sendo o processo produtivo um fenômeno temporal, os gastos necessários para a aquisição dos serviços dos fatores ocorre antes do término da produção da firma e do retorno obtido com o rendimento das vendas. Também, do ponto de vista especifico do equipamento, seu periodo de produção é maior do que um único periodo de tempo operacional onde se dão os investimentos que estruturam o processo produtivo.

Devemos adicionar a esse quadro de tempo embutido nas aplicações em ativos líquidos, os quais são medidos tanto pelo preço, dado no tempo, da taxa de juros ou do dinheiro, "como pelas pressões da incerteza e ignorância que o tempo real envolve" (Vickers, 1987, p 7). Finalmente, tanto a captação de recursos, através da emissão de dívidas futuras, quanto a obtenção de rendimentos monetários prováveis, graças ao uso do capital produtivo, implica ambos os casos em forma de tratamento contratuais que recaem sobre o futuro. Sintetizando, o tempo é tudo para a firma. Dessa observação sobre a relevância do tempo, obtemos o segundo aspecto crucial da ação da firma: a relação da firma para como o tempo é guiada pelo conhecimento que essa possui ao tomar decisões. Entretanto, a qualidade desse conhecimento não permite às firmas tomarem decisões sem incertezas. Isto por que o conjunto de variáveis a ser manipulado pela firma, base de tomada de decisões, não se encontra em seu poder e tampouco é passivel de ser conhecido por técnicas de projeção sobre o futuro.

De um lado, porque há os planos e as decisões a serem tomadas pelos demais agentes, os quais dependem de variáveis que não lhes são disponíveis, de outro lado porque, determinar a priori a direção e os acontecimentos que afetarão os rendimentos futuros, após a implementação da decisão de investimento, torna-se impossivel pelo simples fato de ainda não existirem como tais. Do tempo e da incerteza decorre a importância da moeda. Esta sintetiza as relações entre tempo e incerteza no sentido de que a sua posse pode garantir a passagem do presente para o futuro, dando flexibilidade à ação da firma.

Para garantir, com segurança, essa passagem, a moeda deve manter seu poder de compra no futuro vis-â-vis a um elevado prêmio de liquidez. A causa desse último aspecto deverá residir, primeiro, na inelasticidade de sua oferta e, em conseqüẻncia, segundo, no fato de ser mais rara do que os demais ativos da economia. Daí, para a firma, a posse da moeda torna-se um fim em si mesmo. Quando em posse dessa, a firma pode iniciar o processo produtivo, determinando com isso o nivel do produto e da renda ou simplesmente, graças ao elevado prêmio de liquidez que possui, manter-se liquida, sem aplicações produtivas de seu capital. 
Uma conseqüência, que nos é cara, surge e é determinada pela moeda. Essa, ao regular a atividade econômica, nos termos vistos acima, possibilita a entrada e a saida de produtos individuais do processo de acumulação de capital. Isso se dá em razão de que, para produzir bens, o agente individual tem de apoderar-se da moeda, através de financiamento, geralmente bancário, para realizar os seus investimentos. Sujeito a essa restrição, o produtor deverá transformar seus passivos em compromissos financeiros. Vai dai que,

os termos nos quais os agentes podem fazer esta transformação regula sua iniciação na produção, em dois sentidos. Primeiro, determina financeiramente quais agentes encaminharão seus projetos. Segundo, determina financeiramente o volume total da atividade econômica que pode ser iniciada. Nesse papel de regulador da atividade econômica, o dinheiro aparece, especialmente na perspectiva do agente individual, como um fator independente no qual sua atividade econômica tem que se adaptar (Foley, 1989, p. 251).

Quer isso significar que, na economia monetária, a moeda é administrada pelos bancos e intermediários financeiros que tem o poder de ofertar crédito a cada produtor individual, criando a moeda a ser consumida pelo processo de investimento e bancada, em última instância, pelo poder público.

\section{PORTFÓLIO E PREFERÊNCIA PELA LIQUIDEZ: UM PASSO ALÉM DO MOTIVO ESPECULAÇÃO}

Sendo esses os postulados básicos, no quais convertem a ação da firma, cabe ressaltar, então, que sua atuação será tão mais otimizada, quanto mais se adequa a lógica macroeconômica desse tipo de economia, na qual a moeda ou a liquidez são fatores fundamentais. Logo, a obtenção de rendimentos na forma monetária é, antes, uma qualidade derivada da estrutura econômica enquanto tal, cujos agentes produtivos tomam decisões para inserirem-se nessa dinâmica e se possivel alterarem essa dinâmica a seu favor, crescendo sua inserção nela

Simplifiquemos os problemas envolvidos, reduzindo-os à sua expressão básica de preferência pela liquidez, estratégia de geração de lucros monetários (incluso na composição e o financiamento dos ativos no portfólio) e decisões econômicas da firma (investimento, preço e produção). Pelo exposto, nosso ponto de partida é a preferência pela liquidez, aqui entendida na forma de dominância financeira própria a uma economia monetária de produção que desenvolve todas as possibilidades potenciais que possui, como determinante da dinâmica econômica, vale dizer, como determinante da formação de estratégias de geração de rendimentos monetários excedentes, das decisões econômicas e da estrutura concorrencial dos mercados. Isso posto, em uma situação econômica anterior, quando a economia monetária de produção dá seus primeiros passos, os incentivos empresariais para liquidez são apreendidos de forma precisa pela formulação keynesiana básica. A saber, a demanda pela moeda ou preferência pela liquidez em Keynes é um atributo que já decorre da natureza da economia capitalista.

Especificamente, a preferência pela liquidez decorre dos motivos transaçăo, precaução e especulação. O motivo transação informa a quantidade de moeda necessária ao giro dos negócios, vale dizer, para pagamento de despesas durante o periodo de produção, até o retorno do investimento. O motivo precaução está relacionado aos desembolsos frente aos acontecimentos inesperados e à exploração de oportunidades imprevistas relacionadas à aquisição ou à posse vantajosa de ativos, para saldar compromissos monetários futuros. Finalmente, o motivo especulação, base da preferência pela liquidez, refere-se à demanda por moeda justificada pela expectativa dos agentes, em que haverá mudanças favoráveis no preço dos títulos e, com isso, na taxa de juros. Em 
seus termos, a demanda especulativa por moeda se justifica "pelo propósito de se obter lucros por saber melhor que o mercado o que trará o futuro" (Keynes, 1983, p. 124).

Daí sua formulação seja, $M_{1}$ : o montante de recursos liquidos necessários aos motivos precaução e transação; $M_{2}$ : o montante de recursos líquidos necessários ao motivo especulação. $L_{1}$ uma função de $M_{1}$, relacionada à renda; $e, L_{2}$ : uma função de $M_{2}$ relacionada à taxa de juros do dinheiro, teremos

$$
M \cong M_{1}+M_{2}=L_{1}(Y)+L_{2}(r) \text {, }
$$

o que implica que as variações de $M, Y$ e de $r$ dependem da oferta de $M$. Caso típico nesse sentido, segundo Keynes, é quando ocorre a emissão de moeda pelo Governo. Essa emissão aumenta o nivel de renda, mas sem que a demanda por moeda de M1 seja substancialmente alterada. Nesse caso, parte do novo dinheiro se converte em títulos fazendo recuar $r$ e, ao mesmo tempo, estimulando $Y$, "a tal ponto que o novo dinheiro seja absorvido quer por $\mathrm{M} 2$ quer por $\mathrm{M} 1$, o que corresponde ao aumento de $\mathrm{Y}$ ocasionado pela baixa de r" (Keynes, 1983, p.142)

Tais relações também indicam, no caso de L2 (r), que a demanda por moeda acompanha as variações das taxas de juros. O ponto fundamental aqui é que admitindose que os agentes possam reter moeda, no aguardo de que os preços dos títulos ou que as taxas de juros esperadas se alterem, os agentes formulam, com isso, expectativas que Ihes possibilitam ganhos futuros ao venderem seus títulos a preços mais altos do que quando adquiridos Segundo Keynes:

Podemos resumir a proposição acima estabeiecendo que, em qualquer estado de expectativa, há na mente do público certa inclinação para conservar dinheiro líquido em quantidade superior à que requer o motivo de transação ou o motivo de precaução, que se traduzirá em detenção efetiva de moeda, dependendo dos termos em que a autoridade monetária se acha disposta a criar recursos liquidos. É esta potencialidade que resume a função de liquidez L2 (Keynes, 1983, p. 145)

Em resumo, a retenção de moeda não possui nada de irracional, estando de acordo com o caráter mercantil e de reserva de oportunidade que a moeda sintetiza na economia capitalista. Logo, a preferência pela liquidez vincula moeda e investimento via taxa de juros monetária, esclarecendo uma maneira peculiar pelo qual a acumulação se dá.

Vejamos os problemas daí decorrentes. Ao vincular a moeda à preferência pela liquidez, através do comportamento da taxa de juros, tendo como contraface o efeito dos juros sobre o investimento e, com isso, indicando a dinâmica econômica, Keynes, segundo Hicks (1987), restringiu as implicações da teoria da liquidez afetando seus desdobramentos teóricos e comprometendo a apreensão dos aspectos mais gerais da nova economia em curso Nesse sentido, fez duas críticas fundamentais para demonstrar a limitação da análise keynesiana. ${ }^{1}$

Primeiro, critica a relação estabelecida por Keynes entre títulos e moeda (escolha única estabelecida por Keynes) que se encontra na base do motivo especulação, tanto por ela parecer-lhe uma simplificação excessiva de como se dá o impacto mercado financeiro sobre a ação da firma, e, segundo, critica a afirmação keynesiana de que, no curto prazo, qualquer tipo de investimento é bom para a firma com evidente desprezo para com a produtividade social do investimento e a conseqüente visão distorcida sobre a função

1 É bastante dura a critica de Hicks. Ao seu ver, Keynes realiza essa simplificação para poder compatibilizar com sua análise econômica as medidas de política monetária por ele proposto. Essencialmente, o mote dessa politica é baixar as taxas de juros de longo prazo, suprimindo a especulação e, com isso, aumentando o nivel dos investimentos. Fica a conclusão de que Keynes forçou a análise sobre o rentismo, o que levou ao descrédito sua própria posição de política econômica. Parece ser essa, na visão de Hicks, a crise do keynesianismo. 
social da liquidez. A seu ver, a teoria da liquidez deve ser utilizada para apreender os resultados econômicos surgidos com a introdução nos portfólios da preferência pela liquidez; portanto, algo além daquilo estabelecido pelo motivo especulação. Tudo indica que sua concepção busca compreender as novas condições econômicas do Pós-Guerra, onde a função pública da liquidez consiste em que ela "nos dá tempo para pensar" (Hicks, 1987, p.47).

Seu argumento é o de que, quando se aborda uma economia, onde o mercado financeiro é sofisticado, vale dizer, uma economia onde o controle da liquidez é de alçada dos bancos e da grande empresa, não se pode partir da suposiçăo de que o agente económico possua apenas uma única escolha restrita a reter moeda ou título Parece-lhe que, nessa economia, o agente pode ter motivos reais para optar entre diferentes títulos, de tal forma que, mesmo que haja uma expectativa de baixa,

deverá ser capaz de encontrar algum tipo de titulo de curto prazo, com o qual a perda máxima de capital, num futuro próximo será tão pequena que deverá ser ultrapassada pelos juros recebidos. (...) Assim, o que será afetado pela sua expectativa de baixa não é 'taxa de juros' ...., mas o diferencial entre taxas de curto e longo prazo (Hicks, 1987, p. 39).

Por outro lado, Hicks adverte, na perspectiva da teoria da liquidez, que os ativos físicos dos demais setores da economia são bastante liquidos em si mesmos. Quer demonstrar, com isso, que no portfolio dos outros setores não financeiros o tipo de ativo real (que ele chama de circulante) nele contido gera rendimentos que constituem a parte principal dos lucros, sendo difícil uma divisão que possa expressar a contribuição individual para a composição do lucro total obtido. Ao lado disso, em seu balance sheet, os ativos financeiros tratados como reservas de liquidez, segundo ele, não existem necessariamente como tais.

Contudo, ainda que não existam como tais, e isso é importante para a teoria da liquidez, não se deduz dai que a firma não se encontre líquida; simplesmente porque não possui um poder de empréstimo garantido por um banco. Daí a inobservância da empresa de manter sem seu balance sheet ativos liquidos como reserva. Tal formulação é contrabalançada por um segundo argumento que desenvolve ao introduzir o tamanho da empresa para a apreensão da liquidez. Nesse caso, quanto maiores as empresas, maiores suas necessidades de recursos e menor a capacidade dos bancos em atendê-los totalmente. Frente a isso, a grande empresa se vê obrigada a procurara manter em seu poder ativos líquidos necessários ao seu plano de investimento. Nessas economias, onde há o domínio da grande empresa, diz Hicks, o mercado financeiro comporta-se como mercado de preços flexíveis. Nesse mercado, os aumentos de oferta de moeda, com a conseqüente compra de títulos, acarreta elevação dos preços dos títulos, desencadeando substituições entre titulos, ou a consequiência é o aumento generalizado dos preços de todos os títulos. Daí, primeiro ocorrer uma queda da taxa de juros estimulando o investimento, com a implementação de projetos que anteriormente não eram lucrativos. ${ }^{2}$ Segundo, o aumento do nivel de preços dos títulos aumenta o valor dos ativos financeiros em posse da grande empresa, aumentando sua liquidez.

Por outro lado, ainda que a empresa não possua ativos líquidos, graças ao vínculo mantido com os bancos ou intermediários financeiros, sua liquidez será determinada pela capacidade de obter empréstimos. Nesse caso, a liquidez da empresa vai variar de acordo com a participação dos bancos nos negócios. De qualquer forma, em ambos os casos, a liquidez vai além do motivo especulação e é introduzida na teoria do portfólio revelando

2 Isso só é possível na perspectiva de longo prazo, visto que, no curto prazo, quando a firma investe, perde liquidez ao adquirir um ativo líquido. Se seu grau de liquidez for "duvidoso", uma redução na taxa de juros pode não ter grande incentivo sobre o investimento. Nesse sentido, ver Hicks (1987, p. 43). 
sua natureza. Para Hicks, primeiro, a liquidez resulta de uma seqüencia de escolha permitida pela existência de diversos tipos de títulos a vencerem em prazos diferentes. Aqui o importante a se extrair é que a liquidez ao nos dar tempo para pensar, permite passarmos seqüencialmente do desconhecido ao conhecido. Segundo, liquidez está associada a escolhas flexiveis, no sentido de que não haverá flexibilidade na aquisição de um ativo onde se compromete totalmente no longo prazo, reduzindo-se o leque de escolhas subseqüentes ligadas àquela aquisição. Ao contrário disso, a empresa está liquida quando, ao adquirir um ativo, pode imediatamente desfazer-se dele, sem perdas. Isto é, sem que o preço obtido seja inferior ao que teria ganho se o retivesse por mais tempo. Terceiro, os efeitos maiores da liquidez concentram-se no setor não financeiro, pois é nesse setor que a preferência pela liquidez rebate nos investimentos e, com isso, na atividade econômica. A liquidez aqui exerce a função de dar tempo para pensar sobre as decisões econômicas.

Em sendo essa a natureza da liquidez na economia do Pós-Guerra, ela não apenas expressa a passagem entre o presente e o futuro e tampouco é confundida com o motivo especulação, mas passa a indicar a maneira pela qual ocorre o movimento de financeirização da dinâmica econômica. Esse, se bem compreendo, é o aspecto inovador da visão de Hicks: agora, a relação entre liquidez e produção não pode mais ser buscada apenas na variação das taxas de juros em geral; mas deve se estender à pesquisa para buscá-la no diferencial existente entre taxas de curto e de longo prazos, demonstrando a complexidade do sistema monetário contemporâneo onde a moeda é administrada $e$ criada pelos bancos.

Utilizando-se da argumentação de Keynes e da exposição de Hicks sobre a preferência pela liquidez, pudemos observar quanto o balance sheet das firmas incorpora em seu âmago a problemática da liquidez. Para tarto, complexificou-se a teoria da composição do portfolio a qual previa, fundamentalmente, que a firma, dados o volume liquido de recursos disponiveis, o conhecimento sobre os ativos e os objetivos a serem conseguidos com a aplicação em ativos, disporia-os hierarquicamente em sua carteira, adquirindo-os conforme a eficiência marginal do capital que apresentem. Obviamente, nesse caso, a eficiência marginal do capital, em geral, seria determinada pela liquidez do dinheiro, graças às propriedades de elasticidade de produção e de substituição próxima a zero que apresenta

\section{ECONOMIA MONETÁRIA FINANCEIRIZADA E LIQUIDEZ}

Em contrapartida a isso, o esforço realizado anteriormente foi para demonstrar que a liquidez na economia monetária do Pós-Guerra, não se restringe ao motivo especulação que a retenção de moeda exprime. A liquidez também passa a expressar a situação onde a trajetória da ação da firma não fique comprometida com a aquisição de ativos não facilmente comerciáveis, vale dizer, expressando a condição de flexibilidade da firma.

A compra de um bem facilmente comerciável (...) pode ser também facilmente revogada. Não há diminuição de flexibilidade, a empresa está numa posição quase tão flexivel depois da compra como antes dela. Isto é exatamente o que queremos dizer quando falamos que um ativo comerciável possui liquidez (Hicks, 1987, p.37).

Ao lado disso, a liquidez expressa a situação na qual na ausência de ativos líquidos pela firma, o sistema bancário garante suas necessidades de recursos líquidos, financiando-a. Frisemos esse último aspecto. Como já vimos, a cobertura do sistema bancário não necessita ser integral, pois pode se supor que os fundos líquidos internos preencham parte das necessidades de liquidez da firma, de tal forma que a liquidez, nesse caso, dependerá do volume planejado para investir em relação com os fundos líquidos próprios disponiveis Dai, com elevado nivel de investimento a ser realizado, maior a necessidade de liquidez para sua realização excedendo, dessa forma, presumivelmente, 
os fundos internos disponiveis e demandando financiamento externo.

Portanto, a problemática da liquidez nesse novo quadro, posto por uma economia monetária financeirizada, isto é, onde a liquidez é determinada na macro estrutura financeira (Braga, 1991), a estratégia e a própria trajetória da firma em sua busca de apropriação dos rendimentos excedentes em forma monetária, incorpora, desde então, as condicionantes financeiras anteriormente autônomas frente ao circuito produtivo. Agora em sendo o ponto de partida as interações determinadas pela liquidez, o bem-estar da firma

nâo só depende do comportamento do mercado quanto ao seu volume de produção e das condições em que pode adquirir insumos senão também do comportamento dos mercados financeiros em relação aos termos em que se pode obter empréstimos, vender ativos ou emitir açöes (Minsky, 1987, p.81)

É por essa via que a estratégia de geração de efetivos monetários pela firma pode se sintetizar e expressar sua face contemporânea através da maneira pela qual compõe e financia os ativos de seu portfolio. Essa estratégia articula dois momentos históricos distintos (o custo de transição). Primeiro combina, a) a rentabilidade esperada do ativo. Rentabilidade esta resultante do fluxo de rendimento esperado e seu preço de oferta; $b$ ) sua presumida liquidez, no sentido de que pode, a curto prazo, ser convertido em dintheiro sem perdas e flexibilidade permitida por alavancagens multifuncionais; $c$ ) adiciona a esses dois aspectos as especulações determinadas pelo melhor conhecimento sobre os acontecimentos futuros no mercado.

Segundo, faz emergir a mais recente face da liquidez em seu portfolio, combinando as bases largamente financeiras a estratégias de obtenção dos rendimentos monetários, isto é, para além das quase-rendas que obtém com a utilizaçäo de seu equipamento de capital. E esse é o aspecto fundamental para que sua ação contemple esse novo quadro, sua função objetivo estratégico rearticula o entrelaçamento entre o financiamento próprio, mercados (de fatores e bens), inovações tecnológicas e excedentes monetários institucionalizando, na forma financeira, a preferência pela liquidez.

Essa forma financeirizada da liquidez torna-se a

expressão geral das formas contemporâneas de definir, gerir e realizar a riqueza no capitalismo. Por dominância financeira apreende-se, inclusive, conceitualmente, o fato de que todas as corporações - mesmo as tipicamente industriais (...), têm em suas aplicações financeiras, de lucros retidos ou de caixa, um elemento central do processo de acumulação de riqueza (Braga, 1991, p. 5)

Portanto, se bem compreendo, a institucionalização na forma financeira da preferência pela liquidez permitiu às firmas flexibilizarem seus ativos, como um todo, encaminhando-se para obterem uma conduta estratégica próxima as práticas bancárias. ${ }^{3}$

Por sua vez, é sempre bom enfatizar que o embasamento para a firma formular suas estratégias dessa maneira é o reconhecimento de atuar por sobre uma economia monetaria desenvolvida, onde o meio para possuir controle ou propriedade de ativos reais demanda financiá-los através de créditos fornecidos pelo mercado financeiro. Daí a geração de lucros monetários se encontrar em relação, não apenas com a funcionalidade dos negócios e a segurança em relação a ação do tempo e da incerteza, mas também é o meio pelo qual, através de decisões de investimento, pode ampliar o seu controle e posse sobre a riqueza em geral, subordinando tudo (equipamentos de capital, força-de-trabalho, patrimônio, etc.) a essa questão última. Especificamente do ponto de vista da administração dos portfólios, amplia-se os esforços para a alavancagem multifuncionais as quais visam, "tanto captações quanto aplicações, com prazos e objetivos diferenciados.

3 Braga chama a atenção para a atuação de empresas fora do sistema financeiro que ofertam empréstimos comerciais e ao consumidor indicando progressiva perda de controle dos bancos sobre os sistemas de pagamento 
Capta-se no longo prazo, aplica-se no curto e compöem-se lucros produtivos e financeiros" (Braga, 1991, p.6)

As conseqüências que resuitam desse processo de generalização da liquidez abrem espaços para sua consolidação. De um lado, recombinou-se em fases flexibilidade, liquidez, rentabilidade e especulação, aumentando-se a eficiência marginal geral do portfolio. De outra, intensifica-se a prática especulativa junto às diversas formas de capital, obtendo-se maiores somas de ganhos monetários. Finalmente, altera-se o perfil institucional da própria firma. ${ }^{4}$

Entretanto, ainda que a trajetória da firma, ao adequar-se ao e ao moldar essa nova economia, tenha avançado no controle institucionalizado da liquidez, uma negação aparente nessa trajetória é, ainda, permanente. Ao ter de combinar um conjunto de ativos para obter rendimentos monetários excedentes a firma compõe seu portfólio com ativos reais (forma básica na qual aparece a riqueza na economia capitalista). Para que esses possam gerar fluxos monetários, necessitam entrar em operação. Isso é comandado por uma decisão inicial de investimento que implica em autofinanciamento ou financiamento externo, com a conseqüente redução da posição de liquidez da firma, pela contração de dividas ou incorrendo simultaneamente em ambos os casos

Assim, o financiamento do investimento será a tônica da economia capitalista. Daí a firma combinar sempre a proporção ótima entre recursos próprios e de terceiros para implementar decisões de investimento. Conhecemos esse processo. Em sendo dado o preço de oferta do bem de capital, o montante de fundos internos utilizados no financiamento será, segundo Minsky (1987, p. 118)

$$
P I_{i}, I_{i}=\hat{Q}_{i}
$$

onde $Q_{i}$ é o fluxo de rendimento líquido esperado, $l_{i}$ e indica a parcela do irivestimento financiado com recursos próprios. Por sua vez, a parte financiada externamente será:

$$
P I . I_{i}-\hat{Q}_{i}
$$

onde $I_{j}$ indica o investimento total da firma.

Portanto, decidir sobre como financiar e consolidar o financiamento é uma questão embutida na administração e no perfil do portfolio da firma. É nesse sentido que toda decisão de investimento torna-se uma decisão sobre o financiamento e a composição do portfolio ou mais precisamente sobre o grau de liquidez desejado pela firma em seu balance sheet $O$ investimento transforma-se em um fenômeno financeiro. Nessa perspectiva, as conseqüências da decisão de investimento se esclarecem: é próprio desse tipo de decisão que ocorra uma contração da liquidez da firma, seja porque ao investir com recursos próprios realoca e fixa seus ativos liquidos na aquisição de equipamentos de capital, seja por que ao fazer uso de recursos externos fica comprometido com o controle e injeção de liquidez. Dê-se essa intervenção na liquidez da

${ }^{4}$ Braga caracteriza essa mudança:

$\mathbf{1}^{\circ}$ - o conglomerado de serviços e cálculos financeiros passa a ser o centro das novas corporações, dessas novas firmaș; $2^{\circ}$ - privilegia-se nessas corporações o acesso a capital, a informação, a networks tecnológicos e a mercados globais, via agrupamento de empresas com diferentes funções no interior dos grandes grupos; $3^{\circ}$ - tende a ocorrer, .... o que se chama cross. share holdings; $4^{\circ}$ há uma flexibilização do tempo de renfabilização dos investimentos e também das relações débito e crédito e ainda das relações ativo e passivo; $5^{\circ}$ - ocorre uma combinação simultânea de mobilidade, liquidez, rentabilidade e especulação - incluindo aí os ganhos de arbitragem - na circulação de capitais (Braga, 1991, p. 18). 
firma através da ação do mercado financeiro na forma de funding, isto é, na consolidação do financiamento com a aquisição das emissões de títulos e ações ou através do finance onde essa obtém crédito durante o periodo de produção ou por financiamento com recursos próprios, nega-se à firma o livre curso sobre a riqueza na forma monetária. Superar esse obstáculo significa compor os rendimentos através do mercado financeiro.

De outro lado, a importáncia da decisão de investimento, ancorada em expectativas de longo prazo e no estado de confiança, estar associada à decisões de produção e de preços bem como a natureza produtiva do sistema, permite que a firma refaça essa aparente contradição. Isso é factivel por que as decisões de produção determinam aumentos ou variações no volume de produção e as decisões de preços estão vinculadas à necessidade de se angariar fundos para a expansäo da firma, isto é, no aumento do cash-flow que sustentam àquela decisảo de investimento. Mas o fundamental, nesse processo, baseia-se na maneira pela qual essas decisões recaem sobre a natureza dos ativos reais. Dito de outra forma, essas decisões nos colocam quanto a ausência de liquidez imediata desses ativos são superados no interior de sua própria dinâmica.

Em sua dimensão produtiva, por serem detentores da capacidade reprodutiva, esses ativos possuem, também, a capacidade de preservação do valor "Seja ao regular, através do fluxo da produção corrente, a escassez ou o excesso relativo dos ativos reprodutiveis." Seja ao "proteger seu valor, através da fixação de preços dos bens cuja produção esses ativos servem" (Belluzzo, 1993, p. 94)

Nessa perspectiva, decisões de investimento, produção e preços integram-se aos objetivos de geração de excedentes monetários e a estratégia de manutenção de um grau desejável de liquidez para a firma dando-lhe "tempo para pensar", ao mesmo tempo que Ihe fornece recursos estratégicos para apropriar-se, se possivel, da riqueza líquida, a qual não possui acesso direto. Dai o entrelaçamento entre capital, produção e finanças esclarecer-se à luz da teoria da liquidez. E essa, como vimos, tem no seu aspecto financeiro o seu novo ponto de partida.

\section{BIBLIOGRAFIA}

BELLUZZO, Luis G. de M. La natureza de la moneda y la gestión monetaria. Investigación Económica. n. 203, enero-marzo, p. 77-101, 1993.

BRAGA, Jose C. S. A financeirização da riqueza (A macroestrutura financeira e a nova dinâmica dos capitalismos centrais). Campinas: UNICAMP-IE, 1987

FOLEY, J. A. Money in economic activity. In: EATWELL, J., MILGATE, M. and NEWMAN, P The new palgrave. Londres: The McMillan Press, 1989.

HICKS, J A crise na economia keynesiana. Vértice editora, 1987.

MINSKY, H. P. Las razones de Keynes. México: Fondo de Cultura Económica, 1987. Stabilizing an unstable economy. New York, 1986.

KEYNES, J.M. Teoria geral do emprego, do juro e do dinheiro. São Paulo: Abril Cultural, 1983.

VICKERS, D. Money capital in the theory of the firm. Apreliminary analysis Cambridge: Cambridge University Press, 1987.

\section{ABSTRACT}

\section{THE INSTITUTIONALIZATION OF LIQUIDITY PREFERENCE: A CONTRIBUTION}

This article analyses the firm's behavior in a context of decision for obtain monetary profit. Considering this idea, the article aims at analysing how the firms employ their recurses and institutionalize their methods when the economic system is so volatibe. First of all, there is a discussion about how firms obtain monetary profits. Second, it presents the process in which firms transform psychical recourses into productos. Finally, it discusses how firms use not only real assets but monetary assets to obtain expected monetary profits 